\title{
Hubungan antara Kualitas Tidur dengan Daya Konsentrasi Belajar pada Mahasiswa Kepaniteraan Klinik
}

\author{
Nadhila Shafira Fitri ${ }^{1}$, Nur Afrainin Syah ${ }^{2}$, Asterina ${ }^{3}$ \\ ${ }^{1}$ Fakultas Kedokteran Universitas Andalas, Padang \\ ${ }^{2}$ Bagian MEU Fakultas Kedokteran Universitas Andalas, Padang \\ ${ }^{3}$ Bagian Kimia Fakultas Kedokteran Universitas Andalas, Padang
}

\section{A B S T R A C T}

\begin{abstract}
Latar Belakang. Setiap orang memerlukan kadar tidur yang cukup agar tubuh dapat berfungsi normal. Kurangnya kebutuhan tidur akan berdampak pada menurunnya kemampuan untuk berkonsentrasi, membuat keputusan, dan berpartisipasi dalam aktivitas sehari-hari. Dewasa muda banyak yang mengalami hambatan dalam proses belajar yang disebabkan oleh rasa mengantuk dan lelah akibat kurang tidur. Mahasiswa kedokteran adalah salah satu subkelompok dari populasi yang sangat rentan terhadap kualitas tidur yang buruk. Hal ini diduga karena tuntutan akademis yang tinggi, tugas klinis, pilihan gaya hidup, sampai pekerjaan yang menantang secara emosional.
\end{abstract}

Objektif. Penelitian ini bertujuan untuk mengetahui hubungan kualitas tidur terhadap konsentrasi belajar mahasiswa kepaniteraan klinik FK Unand.

Metode. Jenis penelitian yang digunakan adalah secara analitik dengan metode cross sectional. Teknik pengambilan sampel dilakukan secara stratified random sampling dengan total sampel didapatkan sebanyak 222 orang. Dengan menggunakan kuesioner PSQI dan kuesioner konsentrasi belajar yang kemudian hasilnya dianalisis secara univariat dan bivariat menggunakan uji Chi-Square.

Hasil. Didapatkan sebanyak $65,32 \%$ mahasiswa mengalami gangguan tidur dan $77,48 \%$ mahasiswa memiliki tingkat konsentrasi yang tergolong kurang.

Simpulan. Bahwa terdapat hubungan bermakna antara kualitas tidur dengan tingkat konsentrasi belajar mahasiswa.

Kata kunci: kualitas tidur, konsentrasi belajar, mahasiswa kepaniteraan klinik, koas

Background. Everyone needs enough sleep so the body can function normally. Lack of sleep will result in decreased ability to concentrate, make decisions, and participate in daily activities. Most of the difficulties young adults experience in their learning process are caused by drowsiness and fatigue due to lack of sleep. Medical students are a subgroup of the population who are vulnerable to poor sleep quality. This is thought to be due to high academic demands, clinical assignments, lifestyle choices, and emotionally challenging work.
Objective. This study aims to determine the relationship between sleep quality and the concentration level of clinical clerkship students from Faculty of Medicine, Andalas University.

Method. This is a cross-sectional study. The sampling technique was carried out by stratified random sampling with a total sample of 222 people. By using the PSQI questionnaire and the learning concentration questionnaire which were then analyzed univariately and bivariately using the Chi-Square test.

Result. The results obtained were as many as $65.32 \%$ of students experiencing sleep disturbances and $77.48 \%$ of students had relatively poor concentration levels.

Conclusion. From the Chi-Square test results $(p=0,000)$ it can be concluded that there is a significant correlation between the quality of sleep and the students' concentration level. Keywords: sleep quality, concentration level, clinical clerkship students

\section{Apa yang sudah diketahui tentang topik ini?}

Kualitas Tidur yang buruk dapat mempengaruhi aktivitas sehari-hari.

\section{Apa yang ditambahkan pada studi ini?}

Pengaruh kualitas tidur dan Study From Home (SFH) terhadap tingkat konsentrasi belajar pada mahasiswa kepaniteraan klinik.

\section{CORRESPONDING AUTHOR}

Nama: Nadhila Shafira Fitri

Phone: $\mathbf{+ 6 2 8 1 8 7 5 2 3 0 3}$

E-mail:dhilla_fitri@yahoo.co.id

\section{ARTICLE INFORMATION}

Received: September $23^{r d}, 2020$

Revised: October $15^{\text {th }}, 2020$

Available online: October $31^{\text {st }}, 2020$ 


\section{Pendahuluan}

Setiap orang membutuhkan kadar istirahat dan tidur yang cukup agar tubuh dapat berfungsi dengan normal. Tubuh melakukan proses pemulihan untuk mengembalikan stamina tubuh hingga berada dalam kondisi yang optimal pada saat istirahat dan tidur. ${ }^{1}$ Akan terjadi peningkatan aliran darah menuju serebral saat seseorang tertidur, sehingga otak mendapatkan lebih banyak oksigen yang berfungsi dalam membantu penyimpanan memori dan pembelajaran yang berhubungan dengan fungsi kognitif. ${ }^{2}$ Tidur juga dapat membantu kontrol mood, memori, serta performa kognitif seseorang. ${ }^{3}$

Pola tidur yang baik dan teratur dapat memberikan efek yang baik pada kesehatan. ${ }^{1}$ Perubahan pola tidur umumnya disebabkan oleh tuntutan aktivitas sehari-hari yang menyebabkan berkurangnya kebutuhan untuk tidur, akibatnya sering mengantuk yang berlebihan pada siang harinya. ${ }^{3}$ Kebutuhan tidur seseorang juga dipengaruhi oleh kualitas tidurnya. ${ }^{4}$ Kualitas tidur meliputi aspek kuantitatif dan kualitatif tidur, seperti lamanya tidur, waktu yang diperlukan untuk bisa tertidur, frekuensi terbangun dan aspek subjektif seperti kedalaman dan kepulasan tidur. ${ }^{5}$ Pada kenyataannya, kualitas tidur lebih mempengaruhi kesehatan keseluruhan dibandingkan dengan kuantitas tidur. ${ }^{6}$

Kebutuhan tidur dapat dilihat dari berbagai macam faktor, mulai dari berapa lama waktu yang diperlukan untuk terlelap, seberapa sering seseorang terbangun setelah terlelap, dan jika terbangun di malam hari, berapa lama waktu yang dihabiskan terjaga sebelum jatuh tertidur kembali, serta berapa lama waktu yang sebenarnya dihabiskan dalam keadaan benarbenar tertidur. ${ }^{5}$ Kurangnya kebutuhan tidur akan berdampak pada menurunnya kemampuan untuk berkonsentrasi, membuat keputusan, dan berpartisipasi dalam aktivitas sehari-hari. Dewasa muda banyak yang mengalami hambatan dalam proses belajar disebabkan oleh rasa mengantuk dan lelah akibat kurang tidur, sehingga menurunkan konsentrasi ketika belajar. ${ }^{7}$ Hal ini perlu mendapatkan perhatian yang serius karena gangguan tidur (sleep deprivation) dapat mempengaruhi proses belajar, gangguan memori dan kesehatan emosi. ${ }^{3}$

Mahasiswa kedokteran adalah salah satu subkelompok dari populasi yang sangat rentan terhadap kualitas tidur yang buruk. Hal ini diduga karena tuntutan akademis yang tinggi, tugas klinis, pilihan gaya hidup, sampai pekerjaan yang menantang secara emosional. Selain itu, kualitas tidur yang buruk lebih sering terjadi pada mahasiswa kedokteran daripada mahasiswa nonmedis. Konseptualisasi kualitas tidur sangat penting bagi mahasiswa kedokteran karena berkaitan langsung dengan kinerja akademik dan kognitif mereka. ${ }^{8}$ Bermacam penelitian yang telah dilakukan di berbagai belahan dunia termasuk Iran, Amerika Serikat, Brazil, dan Lithuania menunjukkan rendahnya kualitas tidur di antara mahasiswa kedokteran. ${ }^{9}$ Sementara di Indonesia sendiri, pada penelitian yang dilaksanakan di Universitas Udayana pada tahun 2017 menunjukkan 77\% sampel mahasiswa kedokteran preklinik memiliki kualitas tidur yang buruk. ${ }^{10}$ Penelitian serupa juga telah dilaksanakan di Unand kepada mahasiswa preklinik angkatan 2010 dengan hasil 53\% responden mengeluhkan adanya gangguan tidur. ${ }^{11}$

Konsentrasi belajar merupakan usaha pemusatan pikiran atau perhatian terhadap suatu objek yang sedang dipelajari dengan tidak membagi perhatiannya kepada hal lain dan dilakukan secara sadar oleh individu. ${ }^{12}$ Kemampuan berkonsentrasi mahasiswa akan mempengaruhi kualitas belajar dan akan berdampak pada prestasi belajar mereka. Seseorang tidak mudah mengalihkan perhatiannya terhadap masalah lain di luar yang dipelajarinya apabila sedang berkonsentrasi sehingga diperoleh hasil yang optimal, salah satu contohnya adalah mendapatkan hasil prestasi belajar yang memuaskan. ${ }^{13}$

Berdasarkan uraian di atas penelitian ini dilakukan untuk melihat apakah ada hubungan antara kualitas tidur dengan konsentrasi belajar pada mahasiswa kepaniteraan klinik Fakultas Kedokteran Universitas Andalas.

\section{Metode}

Penelitian ini adalah penelitian analitik dengan menggunakan metode cross sectional, yang dilakukan pada mahasiswa kepaniteraan klinik Fakultas Kedokteran Universitas Andalas. Sampel diambil secara stratified random sampling berdasarkan proporsi tiap rotasi siklus, dengan total akhir jumlah sampel sebanyak 222 orang. Sampel kemudian diminta untuk mengisi 
kuesioner PSQI dan kuesioner konsentrasi belajar. Hasil penelitian kemudian akan dianalisis secara univariat dan bivariat menggunakan uji ChiSquare dengan nilai $\mathrm{p} \leq 0,05$ menunjukkan adanya hubungan yang bermakna.

\section{Hasil}

Karakteristik responden pada penelitian ini dikategorikan berdasarkan angkatan nomor BP, jenis kelamin, siklus yang sedang dijalani, dan berapa banyak siklus yang sudah mereka lalui.

Tabel 1. Distribusi Karakteristik Subjek Penelitian Berdasarkan Angkatan Nomor BP, Jenis Kelamin, Siklus yang Sedang Dijalani, dan Berapa Banyak Siklus yang Sudah Dilalui

\begin{tabular}{lll}
\hline \multicolumn{1}{c}{ Variabel } & $\boldsymbol{f}$ & \multicolumn{1}{c}{$\%$} \\
\hline BP & & \\
2018 & 125 & $56,31 \%$ \\
2019 & 97 & $43,69 \%$ \\
Jenis kelamin & & \\
$\quad$ Laki-laki & 51 & $22,97 \%$ \\
$\quad$ Perempuan & 171 & $77,03 \%$ \\
Siklus yang sedang dijalani & & \\
$\quad$ Anastesi & 11 & $4,95 \%$ \\
Forensik & 11 & $4,95 \%$ \\
Ilmu Bedah & 19 & $8,56 \%$ \\
Ilmu Kesehatan Anak & 20 & $9,01 \%$ \\
Ilmu Kesehatan Kardiovaskular & 13 & $5,86 \%$ \\
Ilmu Kesehatan Kulit dan Kelamin & 12 & $5,41 \%$ \\
Ilmu Kesehatan Masyarakat & 25 & $11,26 \%$ \\
Ilmu Kesehatan Mata & 11 & $4,95 \%$ \\
Ilmu Kesehatan Neurologi & 16 & $7,21 \%$ \\
Ilmu Kesehatan Pulmonologi & 11 & $4,95 \%$ \\
Ilmu Obstetri dan Ginekologi & 20 & $9,01 \%$ \\
Ilmu Penyakit Dalam & 18 & $8,11 \%$ \\
Ilmu Penyakit THT-KL & 9 & $4,05 \%$ \\
Ilmu Psikiatri & 13 & $5,86 \%$ \\
Ilmu Radiologi & 13 & $5,86 \%$ \\
Banyak siklus yang sudah dilalui & & \\
1 - 5 & 55 & $24,77 \%$ \\
6 - 10 & 107 & $48,20 \%$ \\
11 - 15 & 60 & $27,03 \%$ \\
\hline
\end{tabular}

Tabel 2. Gambaran Kualitas Tidur Berdasarkan Hasil Kuesioner PSQI

\begin{tabular}{lccc}
\hline & Kategori PSQI & $\boldsymbol{f}$ & $\mathbf{\%}$ \\
\hline Baik & & 77 & $34,68 \%$ \\
Buruk & 145 & $65,32 \%$ \\
\hline
\end{tabular}

Dari total 222 responden, didapatkan sebanyak 145 mahasiswa $(65,32 \%)$ memiliki skor PSQI buruk yang menunjukkan lebih banyak mahasiswa yang mengalami gangguan tidur dibandingkan dengan 77 mahasiswa yang tidak mengalami gangguan tidur $(34,68 \%)$.
Tabel 3. Gambaran Konsentrasi Belajar Berdasarkan Hasil Kuesioner Konsentrasi Belajar

\begin{tabular}{lll}
\hline \multicolumn{1}{c}{ Tingkat Konsentrasi Belajar } & \multicolumn{1}{c}{$\boldsymbol{f}$} & \multicolumn{1}{c}{ \% } \\
\hline Baik & 42 & $18,92 \%$ \\
Kurang & 172 & $77,48 \%$ \\
Buruk & 8 & $3,60 \%$ \\
\hline
\end{tabular}

Dari total 222 responden, sebagian besar di antaranya $(77,48 \%)$ memiliki tingkat konsentrasi yang tergolong kurang. Sebanyak 18,92\% responden memiliki tingkat konsentrasi belajar yang baik dan hanya 3,60\% yang memiliki tingkat konsentrasi belajar yang buruk.

Pada saat penelitian berlangsung, terjadi peralihan sistem belajar akibat pandemi COVID19 karena anjuran untuk melakukan study from home $(S F H)$. Namun karena masih berstatus anjuran, ada beberapa siklus (IKA, Ilmu Bedah, dan Ilmu Obgyn) yang belum mengimplementasikan sistem tersebut pada saat data primer diambil.

Tabel 4. Gambaran Kualitas Tidur dan Konsentrasi Belajar pada Mahasiswa $S F H$ dan non-SFH

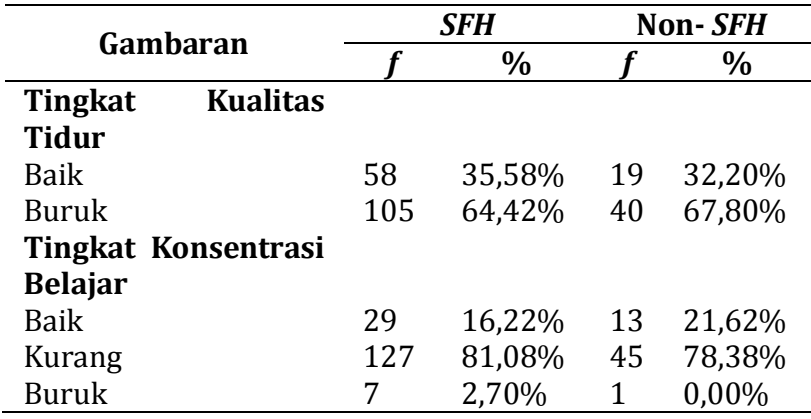

Tabel 5. Hasil Uji Chi-Square Hubungan antara Kualitas Tidur dengan Tingkat Konsentrasi Belajar

\begin{tabular}{|c|c|c|c|c|c|}
\hline \multirow{2}{*}{$\begin{array}{c}\text { Kategori } \\
\text { PSQI }\end{array}$} & \multicolumn{3}{|c|}{ Tingkat Konsentrasi } & \multirow{2}{*}{ Total } & \multirow{2}{*}{$\begin{array}{c}\text { Nilai } \\
\mathbf{p}\end{array}$} \\
\hline & Baik & Kurang & Buruk & & \\
\hline Baik & 24 & 52 & 1 & 77 & \multirow{3}{*}{0,000} \\
\hline Buruk & 18 & 120 & 7 & 145 & \\
\hline Total & 42 & 172 & 8 & 222 & \\
\hline
\end{tabular}

Berdasarkan hasil penelitian yang dilakukan menggunakan uji Chi-Square, didapatkan nilai $\mathrm{p}=0,000$ yang berarti terdapat adanya hubungan yang bermakna antara kualitas tidur dengan tingkat konsentrasi belajar pada mahasiswa program kepaniteraan klinik Fakultas Kedokteran Universitas Andalas. 


\section{Pembahasan}

Dari total 222 responden, didapatkan sebanyak 145 mahasiswa (65,32\%) memiliki skor PSQI buruk. Hal ini sesuai dengan penelitian yang dilakukan oleh Khero sebelumnya pada tahun 2019 yang menyatakan bahwa mahasiswa kepaniteraan klinik lebih mudah mengalami gangguan tidur apabila dibandingkan dengan mahasiswa kedokteran preklinik ataupun dengan mahasiswa program studi lain, seperti program studi hukum dan ekonomi, dikarenakan tuntutan beban kerja fisik dan mental yang lebih berat termasuk stres dalam memanajemen studi lanjutan teoritis dan klinis secara bersamaan. ${ }^{9}$

Secara demografik, studi sebelumnya di Pakistan membuktikan gangguan tidur tampak lebih menonjol pada perempuan. Sementara itu masih belum dapat dibuktikan apakah ada kaitan antara kualitas tidur mahasiswa dengan angkatan BP mereka. ${ }^{14}$

Namun apabila dibandingkan dengan penelitian yang dilakukan Khero -yang mana mahasiswa tahun akhir lebih rentan mengalami gangguan tidur- pada penelitian ini dari ketiga kelompok mahasiswa yang sedang berada di awal, tengah, dan akhir masa kepaniteraan klinik, mahasiswa yang berada di awal dan tengah masa kepaniteraan klinik lebih memiliki kecenderungan untuk mengalami gangguan tidur dibandingkan mahasiswa yang berada pada akhir masa kepaniteraan klinik. Hal ini sesuai dengan pada penelitian serupa di Brazil yang dilakukan terhadap mahasiswa kedokteran dengan hasil $40 \%$ mahasiswa yang mengalami gangguan tidur lebih banyak berasal dari mahasiswa pada tahun pertama dan kedua masa studi kedokteran yang disebabkan oleh buruknya kebiasaan tidur mahasiswa tahun awal, terutama akibat kebiasaan makan tengah malam, menjelajah internet, dan buruknya kehidupan sosial mereka. ${ }^{15}$

Dari total 222 responden, sebagian besar di antaranya $(77,48 \%)$ memiliki tingkat konsentrasi yang tergolong kurang. Sebanyak 18,92\% responden memiliki tingkat konsentrasi belajar yang baik dan hanya 3,60\% yang memiliki tingkat konsentrasi belajar yang buruk. Di antara faktorfaktor yang diperhitungkan, termasuk di antaranya adalah faktor internal seperti keinginan dan motivasi diri, serta faktor eksternal seperti pengaruh lingkungan dan metode pembelajaran.
Hal ini sesuai dengan hasil penelitian Haresabadi yang dilaksanakan terhadap mahasiswa keperawatan Universitas Ilmu Kesehatan Khorasan Utara di Iran pada tahun 2016, di mana bagi sebagian besar sampel, "manajemen waktu yang tepat oleh guru saat presentasi" dan "minat terhadap subjek" terbukti menjadi faktor utama yang memengaruhi konsentrasi belajar. Selain itu faktor-faktor lingkungan, seperti pencahayaan yang tepat dan ventilasi juga merupakan faktor yang paling signifikan. Dari hasil tersebut disimpulkan bahwa, dilihat dari sudut pandang mahasiswa tentang konsentrasi, mengubah beberapa pola perilaku mereka dapat menyebabkan peningkatan tingkat konsentrasinya. Dalam hal ini termasuk perencanaan untuk istirahat yang cukup, memperhatikan kapan saat yang tepat untuk mempresentasikan dan menerapkan topik -yang kemudian akan mendorong siswa untuk belajar secara mandiri- serta menyediakan sarana dan prasarana yang sesuai dengan materi pembelajaran. ${ }^{16}$

Apabila dilihat dari sudah berapa lama mereka menjalani masa kepaniteraan klinik mereka, walau mahasiswa yang berada di awal, tengah, dan akhir masa kepaniteraan klinik semuanya memiliki kecenderungan memiliki tingkat konsentrasi kurang, dari ketiga kategori tersebut mahasiswa yang berada di akhir masa kepaniteraan klinik memiliki tingkat persentase yang lebih tinggi dibandingkan dengan dua kategori lainnya. Berdasarkan penelitian yang dilakukan oleh Pangesti pada tahun 2012, hal ini mungkin disebabkan oleh lamanya mahasiswa mengalami stres akibat tuntutan fisik dan mental, termasuk konflik antar peran mahasiswa kepaniteraan klinik sebagai dokter dan mahasiswa magang yang kemudian mengakibatkan terjadinya kejenuhan. Selain itu, faktor lainnya seperti beban kerja, ambiguitas peran, motivasi diri, serta hubungan dan dukungan sosial di lingkungan kerja juga dapat memengaruhi tingkat kejenuhan pada seseorang. ${ }^{17}$ Kejenuhan umumnya terjadi apabila seseorang mengalami stress pada waktu yang lama dengan intensitas yang cukup tinggi, yang kemudian akan menyebabkan efektivitas pekerjaan menurun termasuk dalam hal ini adalah konsentrasi dalam bekerja. ${ }^{18}$ 
Pada saat sedang mengambil data primer, terjadi perubahan sistem belajar mengajar mahasiswa kepaniteraan klinik akibat dimulainya study from home sebagai antisipasi penyebaran COVID-19 di Sumatera Barat. Namun dalam pelaksanaannya, perubahan sistem belajar tersebut pada saat itu masih berstatus anjuran dan belum merupakan suatu keharusan sehingga setiap siklus memiliki kebijakannya sendiri dalam menentukan apakah pembelajaran dilakukan dari rumah atau tetap di rumah sakit. Perubahan ini berdampak pada berubahnya siklus tidur dan juga lingkungan kerja mahasiswa kepaniteraan dari normalnya.

Dari hasil penelitian terlihat ada sedikit perubahan baik itu pada kualitas tidur maupun tingkat konsentrasi belajar mahasiswa. Program SFH yang baru dimulai mempengaruhi pola tidur mahasiswa karena berubahnya jadwal dan juga beban kerja, terutama beban kerja fisik. $^{9}$ Perubahan pola tidur ini pun kemudian berdampak pada kualitas tidur dan tingkat konsentrasi belajar mereka. ${ }^{19}$

Berdasarkan hasil penelitian yang dilakukan menggunakan uji Chi-Square, didapatkan nilai $\mathrm{p}=$ 0,000 yang berarti terdapat adanya hubungan yang bermakna antara kualitas tidur dengan tingkat konsentrasi belajar pada mahasiswa program kepaniteraan klinik Fakultas Kedokteran Universitas Andalas.

Hal ini sesuai dengan penelitian yang dilakukan Putri pada tahun 2015 dimana didapatkan hubungan yang signifikan antara kualitas tidur dengan konsentrasi belajar.20 Kualitas tidur bergantung pada bagaimana seseorang mempersiapkan pola tidurnya pada malam hari. Kualitas tidur yang buruk dapat memengaruhi kemampuan konsentrasi belajar responden, yang akan berdampak pada turunnya fokus dalam mengikuti belajar mengajar. Kurang tidur menurut beberapa studi dapat menurunkan konsentrasi, atensi, dan kemampuan menyelesaikan masalah. ${ }^{19}$

Hasil penelitian ini juga didukung oleh penelitian oleh Veni pada tahun 2004, dengan adanya perbedaan konsentrasi belajar secara bermakna antara kelompok yang belum dan yang sudah diberikan suplemen Hb. ${ }^{21}$ Hal ini menunjukkan bahwa kualitas tidur yang rendah dapat memengaruhi kejadian anemia karena menurut Potter \& Perry pembentukan darah terjadi pada malam hari dan saat tidur. Anemia dapat mengakibatkan gangguan pada proses belajar seseorang, baik karena menurunnya daya ingat ataupun berkurangnya kemampuan berkonsentrasi. 22

\section{Simpulan}

Berdasarkan penelitian yang dilakukan dapat dilihat ada lebih banyak mahasiswa yang mengalami gangguan tidur $(65,32 \%)$ dibandingkan mahasiswa yang tidak mengalaminya $(34,68 \%)$. Dan sebagian besar mahasiswa memiliki tingkat konsentrasi belajar kurang (77,48\%), dengan sisanya memiliki tingkat konsentrasi baik $(18,92 \%)$ dan buruk $(3,60 \%)$. Dengan hasil uji Chi-Square memperlihatkan nilai $\mathrm{p}=0,000$, maka dapat diperoleh kesimpulan adanya hubungan yang bermakna antara kualitas tidur mahasiswa dengan tingkat konsentrasi belajar mereka.

\section{Ucapan Terima Kasih}

Ucapan terima kasih peneliti sampaikan kepada seluruh pihak yang membantu dalam menyelesaikan penelitian ini.

\section{Daftar Pustaka}

1. Guyton \& Hall. Textbook of Medical Physiology. 11th ed. Singapura: Elsevier (Singapore) Pte Ltd, 2006. Hal 721.

2. Guyton \& Hall. Textbook of Medical Physiology. 11th ed. Singapura: Elsevier (Singapore) Pte Ltd, 2006. Hal 723.

3. Potter, P.A, Perry, A.G. Fundamentals of Nursing. 8th ed. Kanada: Elsevier (Canada) Pte Ltd, 2013. Hal 939.

4. Lanywati, Endang. Insomnia Gangguan Sulit Tidur. Yogyakarta: Kanisius, 2001.

5. Buysse DJ, Reynolds CF, Monk TH, Berman SR, Kupfer DJ. The Pittsburgh Sleep Quality Index: a new instrument for psychiatric practice and research. Psychiatry res. 1989 May 1;28(2):193-213.

6. Hidayat, AA. Kebutuhan Dasar Manusia. Jakarta: Salemba Medika. 2009.

7. Susanto H. Mengembangkan Kemampuan Self Regulation untuk Meningkatkan Keberhasilan Akademik Siswa. Jurnal Pendidikan Penabur. 2006 Dec;7(5):64-71.

8. Satya WR. Hubungan Gangguan Tidur dengan Daya Konsentrasi pada Mahasiswa Fakultas Kedokteran Universitas Sumatera Utara [skripsi]. Medan: Fakultas Kedokteran Universitas Sumatera Utara; 2017.

9. Khero M, Fatima M, Shah MA, Tahir A. Comparison of the Status of Sleep Quality in Basic and Clinical Medical Students. Cureus. 2019 Mar;11(3).

10. Sastrawan IM, Griadhi IP. Hubungan antara Kualitas Tidur dan Daya Konsentrasi Mahasiswa Program Studi Pendidikan Dokter Fakultas Kedokteran 
Universitas Udayana. E-Jurnal Medika Udayana. 2017;6(8).

11. Nilifda $\mathrm{H}$, Nadjmir $\mathrm{N}$, Hardisman $\mathrm{H}$. Hubungan Kualitas Tidur dengan Prestasi Akademik Mahasiswa Program Studi Pendidikan Dokter Angkatan 2010 FK Universitas Andalas. Jurnal Kesehatan Andalas. 2016 Jan 1;5(1).

12. Rahmawati DA. Perbandingan Tingkat Konsentrasi Belajar Anak Sekolah Dasar Dilihat dari Kebiasaan Makan Pagi. BELIA: Early Childhood Education Papers. 2014;3(1).

13. Waliyanti E, Pratiwi W. Hubungan Derajat Insomnia dengan Konsentrasi Belajar Mahasiswa Program Studi Ilmu Keperawatan di Yogyakarta. IJNP (Indonesian Journal of Nursing Practices). 2017 Jun 10;1(2):9-15.

14. Surani AA, Zahid S, Surani A, Ali S, Mubeen M, Khan RH. Sleep quality among medical students of Karachi, Pakistan. J Pak Med Assoc. 2015 Apr 1;65(4):380-2.

15. Corrêa CD, Oliveira FK, Pizzamiglio DS, Ortolan EV, Weber SA. Sleep quality in medical students: a comparison across the various phases of the medical course. Jornal Brasileiro de Pneumologia. 2017 Aug;43(4):285-9.

16. Haresabadi M, Raofian H, Akhlaghi D, Jamchi $H$, Salehi M. Factors Affecting Student Concentration in Classroom: Students' Viewpoints in North Khorasan University of Medical Sciences. Journal of North Khorasan University of Medical Sciences. 2016;8(2):237-44.

17. Pangesti AA. Pengaruh Konflik Peran terhadap Terjadinya Burnout pada Mahasiswa Koass. JPPPJurnal Penelitian dan Pengukuran Psikologi. 2012 Oct 30;1(1):1-6.

18. Tawale EN, Budi W, Nurcholis G. Hubungan antara motivasi kerja perawat dengan kecenderungan mengalami burnout pada perawat di RSUD SeruiPapua. Jurnal Insan. 2011;13(02):74-84.

19. Waliyanti E, Pratiwi W. Hubungan Derajat Insomnia dengan Konsentrasi Belajar Mahasiswa Program Studi Ilmu Keperawatan di Yogyakarta. IJNP (Indonesian Journal of Nursing Practices). 2017 Jun 10;1(2):9-15.

20. Putri AA, Ruhyana R. Hubungan antara kualitas tidur dengan konsentrasi belajar dan indeks prestasi mahasiswa program DIII Kebidanan Stikes 'Aisyiyah Yogyakarta [skripsi]. Yogyakarta: Stikes 'Aisyiyah Yogyakarta; 2012.

21. Veni I. Pengaruh Anemia Terhadap Konsentrasi Belajar Anak Sekolah. Jurnal Pendidikan Dasar. 2004; 5(5):43-50.

22. Potter, P.A, Perry, A.G. Fundamentals of Nursing. 8th ed. Kanada: Elsevier (Canada) Pte Ltd, 2013. Hal 939. 